\title{
Erratum: Table of contents, July 1979
}

Three of the subject headings on the second page of the table of contents of the July 1979 issue of Physical Review $\mathrm{C}$ are incorrect. The portion of the page which contains these errors is reprinted correctly below.

\section{CONTENTS-Continued}

Time-dependent Hartree-Fock calculation of fusion cross sections for the reactions ${ }^{18} \mathrm{O}+{ }^{12} \mathrm{C}$ and ${ }^{16} \mathrm{O}+{ }^{12} \mathrm{C} \ldots$ $\ldots \ldots \ldots \ldots \ldots \ldots \ldots \ldots \ldots \ldots \ldots \ldots$. Krieger and K. T. R. Davies

Simple model for nuclear alignment in peripheral nuclear collisions. . . . . . . . . . R. Vandenbosch ${ }^{12} \mathrm{C}\left({ }^{9} \mathrm{Be},{ }^{9} \mathrm{Be}\right){ }^{12} \mathrm{C}$ (g.s., $\left.4.43 \mathrm{MeV}\right)$ reaction . . . . . J. F. Mateja, A. D. Frawley, P. B. Nagel, and L. A. Parks Intermediate resonances in the inelastic scattering of ${ }^{12} \mathrm{C}$ on ${ }^{16} \mathrm{O} \ldots \ldots \ldots$. Tanimura and $\mathrm{T}$. Tazawa Theory of nucleon transfer in the dynamical two-center shell model . . . . . . . . . . . . . . ..................... Jae Y. Park, Werner Scheid, and Walter Greiner

Fission

Capture-to-fission ratio of ${ }^{235} \mathrm{U}$ in the neutron energy range from 10 to $500 \mathrm{keV} \ldots \ldots \ldots$ Fractional independent yields of ${ }^{139} \mathrm{Ba}$ and ${ }^{142} \mathrm{La}$ from thermal-neutron-induced fission of ${ }^{249} \mathrm{Cf} \ldots \ldots$. Käppeler M. A. Monzyk and D. E. Troutner

Intermediate Energy

Nucleon-nucleon scattering above the pion production threshold . . . . . A. W. Thomas and A. S. Rinat $S$-wave pion-nucleus dynamics in the $\sigma+\omega$ model $\ldots \ldots \ldots \ldots \ldots \ldots \ldots$. . . . . . . . . . . . . . . . . . . . . . Coherent $\pi^{0}$ photoproduction in the isobar-hole formalism . . . . . . . J. H. Koch and E. J. Moniz

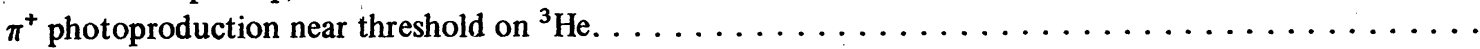

. . . . . . . P. Argan, G. Audit, A. Bloch, N. de Botton, J. L. Faure, C. Schuhl, G. Tamas, C. Tzara, E. Vincent, J. Deutsch, D. Favart, R. Prieels, and B. Van Oystaeyen

Excitation of $E 1$ and $M 2$ resonances via $\left(\pi^{-}, \gamma\right)$ reactions on ${ }^{16,18} 0 \ldots \ldots \ldots \ldots$ . . . G. Strassner, P. Truöl, J. C. Alder, B. Gabioud, C. Joseph, J. F. Loude, N. Morel, A. Perrenoud,

J. P. Perroud, M. T. Tran, E. Winkelmann, W. Dahme, H. Panke, D. Renker, and H. A. Medicus $(\pi, \pi N)$ reactions on ${ }^{25} \mathrm{Mg}$ and ${ }^{197} \mathrm{Au} \ldots \ldots \ldots$. . . . S. Baufman, E. P. Steinberg, and G. W. Butler Properties of the charged photopion production operator and the ${ }^{2} \mathrm{H}\left(\gamma, \pi^{+}\right) 2 n$ cross section. . . . . . . . . . . . . . . . . . . . . . . . E. T. Dressler, W: M. MacDonald, and J. S. O'Connell

Pion-nucleus scattering and absorption as a solution of the Boltzmann equation $\ldots \ldots \ldots \ldots \ldots$ $\ldots \ldots \ldots \ldots \ldots \ldots \ldots \ldots$. Hüfner and $M$. Thies

Differential muon-capture rate for the reaction $\mu^{-}+{ }^{6} \mathrm{Li} \rightarrow{ }^{3} \mathrm{H}+{ }^{3} \mathrm{H}+\nu_{\mu} \ldots \ldots \ldots \ldots$. . . . S. Mintz

\section{Radioactivity}

Proton states in ${ }^{247} \mathrm{Bk}$ excited by ${ }^{246} \mathrm{Cm}(\alpha, t)$ reaction and ${ }^{247} \mathrm{Cf}$ (electron capture) and ${ }^{251} \mathrm{Es}(\alpha)$ decays . . . . . . . . . . . . . . . . . . I. Ahmad, S. W. Yates, R. K. Sjoblom, and A. M. Friedman

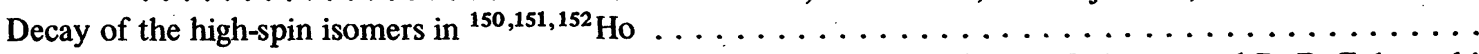
. . . . K. S. Toth, C. R. Bingham, H. K. Carter, B. G. Ritchie, D. C. Sousa, and D. R. Zolnowski 